\title{
Muraling the invisible strings: Collective memory work from an educator inquiry group
}

\author{
Margaret Clark*
}

\begin{abstract}
In this qualitative study of a year-long educator inquiry workshop, nine early childhood educators engaged in the process of collective memory work to critically reflect on how their past experiences as young learners relates to their current teaching practices. Through an iterative analysis of the participants' discussions and writings, this paper highlights how a group of educators shifted their way of thinking about teaching from a series of damage-based memories of restrictive learning environments towards a focus on desire-based stories of transformational and expansive learning experiences. For this group of teachers, this shift became an essential component to identifying how they could begin to work to create liberatory learning experiences and spaces for all students.
\end{abstract}

\section{Article History}

Received: 06 October 2019

Accepted: 08 January 2020

\section{Keywords}

Childhood; Early schooling;

Collective memory work;

Professional development;

Teacher education

\section{Introduction to the Study}

The mapping of my educational history - my memories - again goes back to the origins of why I teach. This helped me see the journey of my teaching as a process, and how events, people and experiences in general connect to one another and to who I am today. It was muraling of the invisible strings that makes the big picture. -Samara, Teacher

For centuries, the concept of memory has been a topic of exploration for philosophers, cognitive scientists, novelists, psychologists, anthropologists, and playwrights. Memories, and the stories connected to them, are used to explain the complexities of the mind and its power to recall past events. In addition, memories have been used to make sense of cultural and social moments and contexts. Over time, a multitude of philosophers and psychologists have worked to understand human memory by using metaphors, including: memories as libraries, melodies on a piano, or even a leaky bucket (Roediger, 1980). Plato described memory as the impression of a seal ring into a block of moldable wax (McDowell, 1973). Freud compared memory to a house, with specific memories as the objects and rooms in that house (Roediger, 1980). Virginia Woolf (2007) called memory a "seamstress" who "runs her needle in and out, up and down, hither and thither. We know not what comes next, or what follows after" (p.436).

Recently, educational researchers and theorists have explored the role that memories of early schooling experiences play in teachers' current pedagogies (Rothenberg, 1994; Van Hook, 2002; ChangKredl and Kingsley, 2014; Miller and Schifflet, 2016). In her research on the autobiographical stories that parents and teachers bring to the classroom, Lightfoot (2004) likened teachers' memories to ghosts that follow us as we move through life. Rothenberg (1994) described how memories are intertwined in teachers' everyday lives and practices:

\footnotetext{
In the case of memories about schooling, things are very thick indeed, and richly informative as well. Being in "the thick of things" encapsulates the inescapability of the presence of memory in everyday life, as something we are always stirring up and moving through. This must surely be the case for teachers in their classrooms, with a background of thousands of hours of memories, and a multitude of classrooms, teachers, and peers from which to draw. Such memories are a vast and varied landscape of personal knowledge, beliefs, and understandings, replete with all the potential riches and problems of a complicated area. (Rothenberg, 1994, p. 369)
}

The concept of memory, specifically the memories of teachers' early experiences of schooling, 
emerged as an important theme in this year-long qualitative study of an educator inquiry group. The group was made up of nine early childhood educators who met on a monthly basis to discuss, reflect and investigate different aspects of teaching young children. During the year, the group spent time reading educational theory and discussing their successes and challenges as teachers. The teachers represented a range of different pedagogies and while they each framed their teaching practices differently, they came together with a common goal of learning from one another and creating a community among educators. The focus on teacher memory emerged from their workshop discussions about why this specific group of teachers choose to teach, with all nine of them describing memories of their schooling experiences as young children as directly related to their current profession.

An analysis of the teachers' discussions and writings revealed that when asked to describe their early memories of learning and school, this group of teachers initially focused on their negative experiences, however after three months of engaging in a practice known as collective memory work, the teachers were able to recall more positive experiences of learning as young children and were able to connect those memories to their current practices. The findings of this study outline how this process of recalling and critically reflecting on memories can help teachers move beyond, even heal, from the emotional pain they may have felt as young children. And in turn, help them re-affirm the encouraging and liberating moments of learning that they aim to create for the young children in their own classrooms. This critical reflective process is posited as a useful tool for promoting thoughtful inquiry among in-service early childhood educators.

\section{Theoretical Framework}

This year-long project was grounded in the concept of a critical reflective practice and its use as a theory and process to uncover, examine, and critique one's current teaching identity and practices (Loughran, 2002; Buchanan and Clark, 2018). Critical reflective practice involves a framework that is based on the idea that through a collaborative inquiry process, one can begin to engage in a practice of critical reflection, working to analyze the social and cultural contexts in which one may be learning and teaching (Buchanan and Clark, 2018). Critical reflective practice emerges from a popularized framework known as reflective practice, first outlined in the work by Donald Schön $(1983,1987)$. Schön's work has become the cornerstone of many teacher education preparation programs across the United States (Loughran, 2002; Richert, 1990; Valli, 1993; Zeichner, 1987). However, despite its popularity, multiple critiques have emerged around the concept of reflective practice (Zeichner and Liu, 2010), noting that the term has become broadly used in only abstract terms, disconnected from the real-world classroom contexts in which educators are learning. Some pre-service teachers have noted that the concept of a reflective practice is something that is simply noted at the "top of every course syllabus" (Buchanan and Clark, 2018). A critical reflective practice framework addresses this gap by including a critical examination that involves specific guiding questions and activities for this reflection. This guide, as noted in the activities used by the educators in this study, gives educators the opportunity to question and examine the power and institutional contexts and dynamics which may influence their teaching and learning experiences (Buchanan and Clark, 2018). A critical reflective practice is additionally grounded in the broader view that all learning and communication is social (Lave and Wenger, 1991; Lave 1996). As these social learning theorists have posited, when learners are provided the opportunity to engage in social interactions, they can work to make meaning together, establishing shared understandings and knowledge about the institutions, contexts, and classrooms in which they learn and teach. The educators in this study were able to use their memories of their early schooling as a tool in their reflective practice, referencing their memories (as noted in the findings section) to make shared meanings and build common understandings among the members of the group.

\section{Review of Literature on Teacher Memories}

Over the past thirty years, multiple researchers have asked teachers to reflect on their early memories of schooling and learning (Rothenberg, 1994; Van Hook, 2002; Chang-Kredl and Kingsley, 2014; Miller and Schifflet, 2016). Researchers have examined how memory plays an important role in the current pedagogical practices and beliefs of educators working with young children. While this body of literature 
Muraling the invisible strings: Collective memory work...

is extensive, there is a lack of research on memory work with teachers that is intensive, involves in-service educators, works with a small group of participants, and is longitudinal in design.

One large-scale study, Rothenberg's (1994) “Memories of Schooling," asked over 400 undergraduate and graduate students to write descriptive essays on their worst and best schooling experiences. Rothenberg discovered that in writing, these students focused on academic challenges and successes, failures and humiliation, competition and fairness, and assessment and transitions. Rothenberg (1994) concluded that, while it is interesting to look at this large body of experiential data from individuals, both educational researchers and teachers could also benefit if memories were to "be examined on a finer-grain level" in a group setting:

These approaches could be more intensive, personal, and collaborative in helping to develop teacher knowledge and insight. They could be analyzed with a small group of people remembering and then adding to memories (Rothenberg, 1994, p. 377).

Building on Rothenberg's research, Van Hook (2002) asked 59 pre-service early childhood teachers at the beginning of their teacher education program to describe, in writing, a significant experience that they remembered from their elementary school years. Van Hook discovered that the teachers mostly focused on their own teachers. A majority of the student teachers $(65 \%)$ recounted negative memories of teachers, while $25 \%$ described positive memories of teachers, and just $10 \%$ described specific interactions with their peers. Based on these findings, Van Hook called for a greater focus on self-reflection in teacher education programs, that "pre-service teachers should recall their memories related to previous school experiences and consider how these memories have impacted themselves and their interaction with teaching pedagogy" (p. 154). Much like other research before and after this, Van Hook highlighted how teacher memories of early childhood and early school experiences, especially the negative and painful ones, may influence one's pedagogical values, beliefs, and expectations (Hollingsworth, 1989; Calderhead and Robson, 1991, Saban 2003). Saban (2003) similarly described how student teachers' negative experiences "endured long in their memories with a lot of hatred of the teachers and his or her subject as the years passed by" (p. 840).

In Chang-Kredl and Kingsley's (2014) research, the authors examined how memories influenced a teacher's reason for entering the profession. When they asked 53 pre-service teachers to write biographical narratives on the topic, the authors discovered that teachers referenced many school and work memories, as well as family memories. These teachers wanted to emulate or oppose past teachers, to fulfill or find present convictions, or to influence or be affirmed by future students (p. 34). These teachers cited memories that were "emotionally charged," either strongly positive or strongly negative, but never neutral. However, in contrast to Van Hook's (2002) findings, the authors discovered that, when asking a teacher about their memories and linking it to the reason why he or she teaches, the majority, almost $75 \%$, were mostly positive reflections. The authors suggested that teacher educators must attend to these "emotional dimensions" when engaging in self-reflection and identity work with teachers, supporting and encouraging teachers to access and articulate how their past connects with their reason for teaching. As a result, Chang-Kredl and Kingsley called for more longitudinal studies on teacher memory in order to more accurately evaluate how it impacted one's identity as a teacher.

In 2016, Miller and Shifflet engaged in similar research and asked 69 pre-service elementary teachers, during a semester-long course, to write about a meaningful memory from when they were students. These students were later asked to connect this memory to their future role as teachers in the field. About half of the students described teachers from their past that they hoped to be like, who had specific characteristics or took actions that were helpful and meaningful to the student. The other half of the students described negative experiences with teachers, which were often associated with some kind of fear. Miller and Shifflet concluded that, like the others in the field, teacher education must foster the art of both recollection and critical reflection to help pre-service teachers both access and analyze their early memories of schooling. However, it is important to point out that in Miller and Shifflet's findings, they noted an outlying trend in their data, a kind of shift or inspiration that emerged among a few of the participants:

An interesting subtheme emerged from the data, as some participants used fear and past experience or teacher to 
create a desired self. A subpopulation of nine participants described their motivation to approach a desired self, by utilizing a negative memory. Using the negative to inspire a positive action was less common in posts; however, these outliers should not be discounted because they illuminate an interesting appendage to the data (p.25).

This particular theme of teachers using their negative memories to explore and imagine a positive, desire-based self and educator, is an important finding to note, as it emerged as a key finding in this study, as described below.

The body of research on teacher memories reveals that this process of reflection is an important one, as the memories of school are directly linked to a teacher's current pedagogies. To further uncover how teacher memories can be used with in-service educators to promote critical and reflective practice, the field calls for research on collective memory work that employs more in-depth research, over a longer period of study, with educators in small groups, and that is collaborative and intensive in design. This project aimed to address this gap in the research by focusing on the following research questions: How do in-service teachers engage and interrogate their own stories and memories of schooling? What patterns emerged from these stories over the course of a year? And, how does the process known as collective memory work help teachers critically reflect on their current teaching pedagogies?

\section{Methods}

This study answers the call for research on teacher memory by using an approach to qualitative inquiry that focused on providing a group of in-service teachers with a collaborative space to engage in indepth discussion and reflection over the course of one year. This research was grounded in the concept that qualitative research is both iterative and fluid, and must adapt to the ever-changing nature of collecting narratives and experiences from participants (Reinking and Bradley, 2008).

\section{Participants \& Project Design}

The participants of this study were nine female early childhood educators from two rural cities in upstate New York in the United States. These nine educators taught in a variety of school settings and hailed from different pedagogical backgrounds and styles. One was Montessori-trained, two were ReggioEmilia-trained, and one was earning her masters in Early Childhood Education through an online program that focuses on "culture-centered" early childhood education. The remaining five teachers cited a mix of pedagogical styles that influenced their teaching, including project-based learning and emergent curriculum. All of the names used in this paper are pseudonyms for the participants. These participants were purposefully selected and invited to this group based on their range of experiences in education, their pedagogical beliefs and practices, and their willingness to join a group that would meet over the course of one full year. Of the nine participants, seven of them came from privately-funded programs and two worked in publicly-funded programs. The participants had range of experience in the teaching profession, from 2 years up to 38 years of experience. The sample size was purposefully kept to a small number of participants to foster discussion.

During this study, the workshops were designed and facilitated to encourage in-depth discussions and writing. Throughout the year, the participants were asked to engage in multiple activities that involved writing down their memories of early learning and schooling, and then asked them to share and discuss them with one another. Over the course of one year, they remembered, described and discussed their first memories of school, influential educators from their past, transitions they made from school to school, and the emotional impressions that different schools or classroom environments made on them. They shared their memories by reading aloud what they had written, summarizing what they had recalled, or describing their stories according to the specific prompts they were given. During these discussions, the teachers were asked to reflect on how these memories connected to how they currently teach and care for young children. This kind of reflection and discussion is what is known as collective memory work. Collective memory work involves participants responding to a set of prompts about their memories of a specific event or topic, through writing or discussion, and then analyzing these narratives with a collective research group (Crawford, Kippax, Onyx, Gault and Benton, 1990, 1992; Haug, 1987; Ovens and Tinning, 2009). The goal of this work is to "achieve intersubjective understanding" among the participants of their 
experiences in specific past settings (in this case, experiences with early schooling and learning) (Ovens and Tinning, 2009, p.1126).

\section{Data Collection \& Analysis}

Over the course of the year, with approval from an institutional review board, the following types of data were collected from 10 two-hour workshops and 4 one-hour interviews with the participants: (1) textual productions from the monthly workshops (written narratives and artifacts, questionnaire responses, journal entries, and interviews); (2) audio recordings of the workshops and interviews; and (3) field notes and memos. The audio recordings were transcribed, and along with the field notes and written artifacts, were coded by major themes that emerged from the narratives. The themes were analyzed according to each individual participant, as well as the group as a whole, using an inductive process of open-coding and memoing (Patton, 2002). These codes and themes were shared with the participants throughout the project, allowing for their response and adjustments to the common understandings of the group. In addition, the principal investigator of the project, who served as the facilitator or the workshops wrote a series of memos based on notes and jottings from observations of the workshop discussions. These memos were guided by the following questions: What topics were emerging in the workshop discussions that referenced one's memories, especially when connected to a teacher's current pedagogical choices and practices? What role did memory play in the discussion of teaching and learning? And lastly: what kind of memories of early learning and schooling were referenced in the discussions? These memos were used to better understand and map the major themes and topics that continued to arise during the workshop discussions and how these topics could inform the next stages and direction of the workshop activities. At the conclusion to the project, all of the data was re-coded and analyzed according to the conversational turns in the workshop discussions, noting when and how the topic shifted in the discussion, comparing these shifts and themes with my field notes from the discussions. After passing through the data multiple times, the major trends that emerged over the course of the year was shared with the group, as a check for both clarity and validity.

\section{Findings from the Study}

An analysis of the data from this study revealed that the memories that teachers have of their early schooling experiences are emotionally charged, with the teachers passionately recalling both negative and positive experiences of learning. The data revealed a specific shift from negative memories that were shared at the beginning of the project to more positive, desire-based memories towards the end of the project. The shift started to occur during the fifth workshop after the group read and discussed the research by Eve Tuck (2009), who describes the concepts of damage and desire-based research. In her work on the ethics of social science research and educational research, Tuck (2009) calls for a moratorium on solely "damagecentered" research on communities, studies that describe communities, neighborhoods or even cultures as "defeated or broken" (p.412). Citing bell hooks, Tuck stated her concern about this kind of research:

I am concerned with... research that invites oppressed peoples to speak but to "only speak from that space in the margin that is a sign of deprivation, a wound, an unfulfilled longing. Only speak your pain (hooks, 1990, p. 152)

Tuck asks communities and peoples to "consider the long-term repercussions of thinking of ourselves as broken" (p.409). During a discussion on Tuck's research in the educator inquiry group, three of the teachers, Bree in particular, discussed how this work resonated with their way of thinking about their teaching, their students of color, and the communities in which they work. In particular, our group discussed Tuck's urging or "cautionary note" to not see desire as a replacement or opposite to damage, but instead to conceive a desire-centered story as a complex one, which acknowledged the pain and damage but focused on the positive aspects, including survival. The teachers discussed how they hoped to acknowledge and recognize not just the broken and pained experiences of their own histories but also to describe their memories of positive learning experiences and moments.

\section{Stories of Damage}

During the first four workshops, seven out of the nine teachers wrote about and shared memories 
that were based on negative experiences, controlling teachers or restrictive environments related to their early schooling, despite the open-ended prompts. One early example of this occurred after they created maps of their memories of early learning experiences. One teacher, Laurel, admitted that she couldn't remember a single name of any of her elementary school teachers. She had attended one of the largest public schools in New York City, and she only remembered the emotions she felt about certain teachers, such as "the scary ones", or "the angry ones". She recalled specific details such as how some of those teachers dressed, even the shoes that they wore, but not their names - noting this was a "major block" in her memory of school. Two of the teachers, Laurel and Alison, described how their teachers spoke to them, treated them, or disciplined them for their personalities or behavior. In the excerpt below, Laurel talked about being reprimanded on her first day of kindergarten:

I had an experience of all of my early, early stuff ... one of the first things that I wrote down was that I got put in the corner on my first day of kindergarten, I remember what I was wearing, I remember how excited I was, I took a banana peel and I danced it across the table and I got put in the corner and I remember feeling so horrified, and I couldn't figure out what I had done, it was a whole visceral memory. -Laurel

Alison described a memory from her nursery school classroom:

I was told I was shy and I didn't have any friends ... we would go around in a circle and say if you are a son or a daughter and I thought girls are bright like the sun and I said "I'm a sun!" and they said no you are not, you are a daughter, and I was like "but I want to be a sun!" These moments-those are what stuck out - these moments of someone telling me something that didn't feel like I am. -Alison

Five of the teachers described some of the negative feelings associated with the structures in a school or classroom setting. Anya described the fear of getting lost or being late to class. Mara and Samara both described not feeling emotionally "safe" in their classrooms. Renee described the stress of taking tests at an early age and how she "shut down" as a result of such anxiety:

I had an experience in second grade - the one that I remember- I had my first anxiety attack ever, hyperventilatingin fifth grade because I couldn't test well and it set up a whole paradigm for the next two plus years of failing in school and I was placed in junior high-I was placed in lower level classes and I was excelling at them, I was bored, but I can't test-I had just shut down. - Renee

\section{A Shift to Desire-based Memories}

During the sixth workshop, one month after the teachers had read Tuck's (2009) work, all but one of the teachers began to reflect on positive memories of their early learning, which were often outside of the school or classroom setting. In these memories, the teachers described moments of learning with their friends, family and mentors.

For one specific teacher, Bree, the experience of desire-based learning emerged once she left the traditional setting of school. At the age of twelve, Bree left school and joined a community of family friends who were engaged in "unschooling" - the process of learning according to your own interests and choices as a young student of the world. Bree described the moment when she decided to leave school - what she described as an "expansive moment":

I think, what like stuck out to me in the process of writing this was this-I guess for me, were politicizing moments or moments where I know something shifted in my awareness of the world. An expansive moment, where the world got larger. My understanding of things got larger, and they are very specific moments in my life. I guess, my unique experience was leaving school - the act of leaving school at 12 years old and trying to figure out my own thing, that's when I got really interested in the theory behind schooling and learning.- Bree

Bree went on to note how the "world got larger" for her, and she described the different kinds of mentors she met during these years and how they affected her in positive ways, including models for how she wants to presently work with children:

What I like thinking about is the different people who influenced me is that I feel attached to the idea of the kind of adult or educator that I want to be in a kid's life... it's nice to think about all these different people who have really different personalities and really different approaches and influenced me in different ways, some were super buddies and some were not, but really made an impact anyway so its kind of nice to think about the different models for good educators - Bree 
Muraling the invisible strings: Collective memory work...

Two of the teachers, Mara and Ella described how their family played a role in their early learning experiences.

I was really surprised how much my sister was present and often how often my memories that I had - I was doing this, she was doing that - this was really paired, when I was thinking about the good emotional counterparts of [those memories]. - Ella

Family was main theme in Mara's writing and discussion over the course of the entire year of the project. In the following excerpt, Mara wrote about a moment in her childhood that reflects her current work with children:

It was a sunny, bright day. Warm. I was on the driveway, a wide, light colored cement driveway, not very long, the
led up to a modern home and which had a low, stone wall running along one side and grass along the other. I think
my uncle and I had been using the hose on the driveway because I remember the color of wet cement. The activity
we were undertaking was pulling the petals off of flowers and placing them in cardboard egg cartons so my
grandmother could plant the seeds the following spring. When we were done, we carried the egg cartons into the
laundry room where they were placed on shelves to be stored until spring.

This memory had always been strong, but it became revelatory in my mid 30s, when for some reason I was engaged in pulling petals off of marigolds and was broadsided by a smell that was SO familiar and in an instant pulled forth the imagery of that day in Colorado. - Mara

In this memory, Mara reflected on the role that her family members, specifically her uncle, played in her learning about seeds and plants. Mara described this memory two other times during the school year, as a very concrete, visceral memory that involved her senses, the sight of the wet concrete and the smell of the flowers. Mara continued on in her writing to reflect on how that memory impacted her perspective on working with young children:

That moment of brilliant illumination was profound! It moved me! ...Knowledge in this form is visceral. It contains sight, sound, relationships, smells. It comes from a place and was part of an activity that was a part of daily life. This approach to knowledge is the knowledge I want to be able to somehow share. Knowing that what I do with children is relevant now, in time, and that it has the potential of re-entering their lives or growing with them through their lives as time progresses, as their lives develop and unfold. That what we do now, what we talk about now, what we discover now, what we question and explore now, has the possibility of living within them and informing them in ways that will be theirs, their story, their memories, their moving forward into and through their lives. - Mara

Here, Mara emphasized the importance of using collective memory work as a framework for both reflecting on one's own teaching practices and acknowledging how influential early learning experiences and environments are to minds and lives of young children.

\section{Discussion}

Understanding the role of memories and how they relate to the everyday lives of teachers is both broad and complex. During the course of this year-long educator inquiry workshop, a group of early childhood educators were able to access, reflect, and conceive of memory in a different way than prior research from the field. In this process of reflecting on their own memories of learning, the educators initially described negative instances of schooling. However, with additional and deeper reflection and discussion, they began to share more positive, desire-based stories of learning, which then connected to the kind of teachers they wanted to be today.

In this study, the process of revisiting memories based on the discussion and reflection among the group highlighted an important role that the social context of the group played throughout the project, where memory was not an individual, strictly cognitive-based, neutral act but one that was strongly influenced by the setting and culture of the group and the context. In this way, memory became a situated practice. Ovens and Tinning (2009) described memory, or what they referred to as reflection, using this sociocultural perspective. These authors noted that the use of reflection in professional development and teacher education had grown in popularity over the past 20 years (Clarke and Chambers, 1999; Loughran, 2006; Tinning, 1995). Ovens and Tinning (2009) noted that often the tool of reflection, or using memory, in teacher education had been used to assist teachers in acknowledging how their own experiences and knowledge shapes their "identities and actions as teachers" (p. 1125). However, these authors argued that by viewing memory as a tool and or process, researchers regarded the teacher as a "neutral, self-conscious 
agent capable of rational analysis" rather than as an individual socially situated in a specific context. In their research, Ovens and Tinning demonstrated how a group of student teachers, engaged in this kind of group memory work, affected one another. The researchers found that "the nature of the discourse community in which the individual is situated enables different forms of reflection" (pg. 1130). Much like Ovens and Tinning (2009), the teachers in this study were also influenced by the way that they shared with one another, and the social context that they had created. For this community of teachers, their collective memory work became a situated practice, where memories were not neutral but directly related to their sharing processes within the group.

When asked if they felt that this kind of collective memory work was important to their current work, all nine teachers responded positively. Bree described how this work encouraged her to dig deeper into her memories but with a new kind of lens, that of an educator:

The workshop activities led me to wanting to dig more into my past...bring up memories of learning and schooling and look at them now through the lens of an educator ...The process ...is absolutely important for educators. It is essential to our growth and skills of reflection and self-development. It's also deeply gratifying and feels like an important form of acknowledgement for a role that often can feel isolating or underappreciated. Feels so important to be thinking/working on larger threads and ideas when classroom time often feels so immediate in its day-to-day demands ....-Bree

For this group of educators, memories and the process of reflecting on those memories became an essential tool in the process and journey of becoming an educator and caregiver of young children. Below is Mara's written response to a prompt asking how collective memory work can impact an educator's reflection on pedagogy:

Memories. They are key to me and have been for as long as I can remember. And that is a long time. They go back to when I was $2 \frac{1}{2} 2$ years old. And they are vivid. They are film clips. They include visual, olfactory, emotional, tactile information. They include important memories of people and places, of activities, of myself and most importantly, how everything made me feel. A range of feelings, responses to events, occurrences, things I saw or felt or heard or smelled.

The importance of having held these memories for so long, and having always considered them somehow important, is that the memories are my sense of self, known only to me. Known only by me, they are the sense of self that supports me, that I wrestle with, that I feel have failed me, they show me my strong side and my weak side, that remind me I always have more work to do. They are battered against and forgotten, only to be remembered again. But, very importantly, they remind me that I am from a time and place. I had an origin and who and what I am now, has continually emanated from the place of origin. I consider it my truest self. My newest self. My enduring self. A self I can go back to. And this is something that supports my work with young children. The early information, the early relationships being formed with things, places and spaces, people, ideas and actions, desires. I must always remember my very dimensional self at those early ages. It is a way in and over time. It is in and of the children I am working and growing with.

What I know now, after half a century of observing and reflecting on my own experiences as a learner, a seeker of knowledge, is that what we learn in our earliest years can often pop-up, through memory, so many years later and support our understanding as older learners.

I think this perspective will aid me in recalling details of my life that have contributed and lead me to where I presently stand in time, as an educator. It may aid me in unfolding my story in a way that is interesting and relevant to others, and which in the process, might serve as a tool, to usher me forward in this work that I do. - Mara

Like Mara, many of the teachers in this group initially connected to the most negative memories of her schooling experiences but were able to, with time and support from the group, access more positive memories of their childhoods. For Mara, it was these positive memories that helped her understand something deeper about what she calls her "truest" self, or an "enduring self." This focus on endurance here, is important, as endurance, the process of sustaining something or bearing with patience, is what many of these teachers have noted as a key component to their work with young children in the institution of schooling and education. When sharing their negative experiences, the teachers described restrictive and controlling environments, so this ability to endure those settings, overcome that pain, and emerge from that experience as an adult with a purpose to create transformative and expansive learning environments is one that is admirable. This group of teachers was able to demonstrate a shared commitment to working together to heal their pain, and imagine what type of educator that they can be in the lives of young 
children, knowing that they too, are creating the memories of learning that has the power to impact these children's lives and paths for many years to come.

\section{Conclusion}

In sum, collective memory work requires extensive critical and reflective analysis of one's early memories, a collaborative space for sharing, a group committed to engaging in such work together, and time to acknowledge the pain and damage one might have experienced in schooling and move towards remembering and connecting to the memories that were focused on the positive. As Samara had noted, working with one's memories involves a complex muraling process of strings and stories that sometimes feel invisible to us. By engaging in collective memory work, educators can make those strings visible and collaboratively work to make meaning of those experiences. It is the complexities and challenges of this work which also leads to the limitations of the study - as we work to understand our memories and how they relate to our current teaching practices, we may also begin to see a re-imagining of those memories. They are, like Plato imagined, impressions in a moldable wax - which can shift and change as we work with that wax, molding it in our collective processing.

It is important to note that this kind of work must not simply involve a recall of the memories of early learning, but must also include a process of questioning the larger contexts in which the early learning occurs - including the power that teachers hold in the classroom, the structures and ways that adults and children interact, the rules and rigidity that exist within a schooling institution. By examining, naming, and acknowledging these contexts, in-service teachers, as they did in this study, can begin to move to imagine alternative, liberatory, expansive and transformative learning spaces where children's voices and choices are acknowledged and respected. Using a combination of collaborative, critical reflection, teachers can engage in collective memory work that acknowledges the pains of early learning but focuses on the possibilities of learning for all students.

In the current state of early education in the United States, educators are facing an educational landscape that involves increased academic pressure and a growing focus on standardized methods of instruction and assessment. With this increased focus on academic rigor, early childhood educators may find themselves struggling to create play-based and liberatory learning environments for the learners in their classroom. Opportunities to reflect on how they were offered these kind of spaces as a young child is an essential element to identifying how they can currently create them. While this kind of work and space is challenging to find and sustain, this group demonstrated that with time, this kind of work helps sustain itself as teachers continue to imagine and embody the care and kindness that they promote in their students. By collaboratively reflecting on their memories, these teachers were able to see themselves as learners on a life-long journey, with the ultimate goal of ushering them forward in this important work that they do.

\section{Declarations}

Acknowledgements: Memories are personal and I would like to thank all of the teacher participants who were willing to share their very personal memories with me for this project. I enjoyed every time we met and will always remember how we celebrated and honoured our group and our students.

Competing interests: The author has no competing interests.

Funding: This manuscript and work was not funded by any funding agency or grant.

\section{References}

Buchanan R., \& Clark, M. (2018). At the top of every syllabus: Examining and becoming (critical) reflective practitioners. In D. Garbett \& A. Ovens (Eds.), Pushing boundaries and crossing borders: Self-study as a means for researching pedagogy, Herstmonceux, UK: SSTEP

Calderhead, J., \& Robson, M. (1991). Images of teaching: Student teachers' early conceptions of classroom practice. Teaching and Teacher education, $7(1), 1-8$.

Chang-Kredl, S., \& Kingsley, S. (2014). Identity expectations in early childhood teacher education: Pre-service teachers' memories of prior experiences and reasons for entry into the profession. Teaching and Teacher Education, 43, 27-36. 


\section{Margaret CLARK}

Clarke, B. L., \& Chambers, P. A. (1999). The promotion of reflective practice in European teacher education: Conceptions, purposes and actions. Pedagogy, Culture \& Society, 7(2), 291-303.

Crawford, J., Kippax, S., Onyx, U., Gault, U., \& Benton, P. (1990). Women theorizing their experiences of anger: a study using memory work. Australian Psychologist, 25(3), 333-350.

Crawford, J., Kippax, S., Onyx, J., Gault, U., \& Benton, P. (1992). Emotion and gender: Constructing meaning from memory. London: Sage.

Haug, F. (1987). Female sexualization: A collective work of memory. London: Verso

Hollingsworth, S. (1989). Prior beliefs and cognitive change in learning to teach. American Educational Research Journal, 26(2), 160-189.

hooks, b. (1990). Yearning: Race, gender and cultural politics. Boston: South End Press

Lave, J. (1996). Teaching, as learning, in practice. Mind, Culture, and Activity, 3(3), 149-164.

Lave, J., \& Wenger, E. (1991). Situated learning: Legitimate peripheral participation. New York, NY: Cambridge University Press

Lightfoot, S. L. (2004). The essential conversation: What parents and teachers can learn from each other. New York: Ballantine Books

Loughran, J. (2002). Effective reflective practice: In search of meaning in learning about teaching. Journal of Teacher Education, 53(1), 33-43.

Loughran, J. (2006). Developing a pedagogy of teacher education: Understanding teaching and learning about teaching. New York, NY: Routledge.

McDowell, J. (1973). Plato-Theaetetus. Oxford, England: Clarendon Press

Miller, K., \& Shifflet, R. (2016). How memories of school inform pre-service teachers' feared and desired selves as teachers. Teaching and Teacher Education, 53, 20-29.

Ovens, A., \& Tinning, R. (2009). Reflection as situated practice: A memory-work study of lived experience in teacher education. Teaching and Teacher Education, 25(8), 1125-1131.

Patton, M. Q. (2002). Qualitative research \& evaluation methods (3rd ed.). Thousand Oaks: SAGE Publications, Inc

Reinking, D., \& Bradley, B. A. (2007). On formative and design experiments: Approaches to language and literacy research. New York: Teachers College Press.

Richert, A. E. (1990). Teaching teachers to reflect: A consideration of programme structure. Journal of Curriculum Studies, 22(6), 509527.

Roediger III, H.L. (1980). Memory metaphors in cognitive psychology. Memory \& Cognition, 8(3), 231-246.

Rothenberg, J. J. (1994). Memories of schooling. Teaching and Teacher Education, 10(4), 369-379.

Saban, A. (2003). A Turkish profile of prospective elementary school teachers and their views of teaching. Teaching and Teacher Education, 19(8), 829-846.

Schön, D. A. (1983). The reflective practitioner: How professionals think in action. New York, NY: Basic Books

Schön, D. A. (1987). Educating the reflective practitioner: Toward a new design for teaching and learning in the professions. San Francisco: Jossey-Bass

Tinning, R. (1995). We have ways of making you think, or do we? Reflections on 'training' in reflective teaching. In C. Pare (Ed.), Training of teachers in reflective practice of physical education (pp. 21-52). Trois-Rivieres: Universite du Quebec a Trois-Rivieres

Tuck, E. (2009). Suspending damage: A letter to communities. Harvard Educational Review, 79(3), 409-428.

Valli, L. (1993). Reflective teacher education programs: An analysis of case studies. In J. Calderhead \& P. Gates (Eds.), Conceptualising reflection in teacher development. London: Falmer.

Van Hook, C. W. (2002). Pre-service teachers reflect on memories from early childhood. Journal of Early Childhood Teacher Education, 23(2), 143-155.

Woolf, V. (2007). The Selected Works of Virginia Woolf. Hertfordshire, UK: Wordsworth Editions

Zeichner, K. M. (1987). Preparing reflective teachers: An overview of instructional strategies which have been employed in pre-service teacher education. International Journal of Educational Research, 11(5), 565-575.

Zeichner, K., \& Liu, K. Y. (2010). A critical analysis of reflection as a goal for teacher education. In Handbook of reflection and reflective inquiry (pp. 67-84). Boston, MA: Springer 